\title{
EFFECT OF BROMELAIN AND ARNICA COMBINATION ON PERIORBITAL EDEMA AND ECCHYMOSIS IN SEPTORHINOPLASTY
}

\author{
ONER SAKALLIOGLU ${ }^{1}$, EMRAH GÜLMEZ ${ }^{1}$, YAVUZ SULTAN SELIM YILDIRIM ${ }^{1}$, \\ HASAN CETINER ${ }^{2}$, SERTAC DUZER ${ }^{1}$, and NIHAT SUSAMAN ${ }^{1}$ \\ ${ }^{1}$ Elazig Fethi Sekin Sehir Hastanesi \\ ${ }^{2}$ Special East Anatolian Hospital
}

January 26, 2021

\begin{abstract}
Purpose: The aim of this study to investigate the effect of bromelain-arnica gel combination on periorbital edema and ecchymosis seen after open septorhinoplasty. Methods: Sixty patients who performed open septorhinoplasty with osteotomies were included to the study. These patients were allocated into two groups: in group 1, 30 patients as control and in group 2, 30 patients as study group who were treated with topical bromelain-arnica gel after surgery. Scoring of eyelid edema and peroirbital ecchymosis were evaluated on the first, third and seventh postoperative days using scale of 0 to 4 used by observers. Results: We observed that the administration of topical bromelain-arnica gel after surgery was effective clinically and statistically in decreasing the score of both edema and ecchymosis in open septorhinoplasty with ostetomies. In group 2 patients, periorbital edema and ecchymosis scores were significantly lower compared to control group $(\mathrm{p}<0.05)$. Conclusions: Our results support that topical administration of bromelain and arnica gel combination provided both clinically and statistically significant reduction in periorbital edema and ecchymosis following septorhinoplasty.
\end{abstract}

\section{EFFECT OF BROMELAIN AND ARNICA COMBINATION ON} PERIORBITAL EDEMA AND ECCHYMOSIS IN SEPTORHINOPLASTY

\section{ABSTRACT}

Purpose: The aim of this study to investigate the effect of bromelain-arnica gel combination on periorbital edema and ecchymosis seen after open septorhinoplasty.

Methods: Sixty patients who performed open septorhinoplasty with osteotomies were included to the study. These patients were allocated into two groups: in group 1, 30 patients as control and in group 2, 30 patients as study group who were treated with topical bromelain-arnica gel after surgery. Scoring of eyelid edema and peroirbital ecchymosis were evaluated on the first, third and seventh postoperative days using scale of 0 to 4 used by observers.

Results: We observed that the administration of topical bromelain-arnica gel after surgery was effective clinically and statistically in decreasing the score of both edema and ecchymosis in open septorhinoplasty with ostetomies. In group 2 patients, periorbital edema and ecchymosis scores were significantly lower compared to control group $(\mathrm{p}<0.05)$.

Conclusions: Our results support that topical administration of bromelain and arnica gel combination provided both clinically and statistically significant reduction in periorbital edema and ecchymosis following septorhinoplasty. 
Key Words: Septorhinoplasty, Edema, Ecchymosis, Arnica, Bromelains

\section{WHAT'S KNOWN?}

Totonchi et al. investigated the effect of steroids and arnica following rhinoplasty and divided the patients into three groups: group P received steroids, group A received arnica, and group C (control group) received no medication. The results demonstrated that both steroids and arnica could be effective in reducing edema during the early postoperative period.

A previous study evaluated the effect of arnica and bromelain combination on ecchymosis after blepharoplasty. A total of 130 patients received the tablet forms of arnica and bromelain for a total of two weeks, one week before surgery and another week after surgery, while the control group received no treatment. The authors concluded that no significant difference was found between the two groups with regard to ecchymosis.

\section{WHAT'S NEW?}

This study, we applied bromelain-arnica gel combination topically to the patients' ecchymosis and edema around their eyes, and we also observed that topical application of bromelain-arnica gel combination was effective to significantly decrease patients' both ecchymosis and edema.

Septorhinoplasty is highly popular and the number of patients undergoing this procedure is growing worldwide. But, periorbital edema and ecchymosis following septorhinoplasty can cause to significant increase in morbidity and a significant decrease in patient satisfaction. Although, there are numerous studies investigating the reduction of periorbital edema and ecchymosis, and post-rhinoplasty care remains controversial. In this study, we investigated the efficacy of topical administration of bromelain and arnica gel combination in the reduction of periorbital edema and ecchymosis following septorhinoplasty, and we compared the results with those of control group in a randomized fashion. In conclusion, this study indicated that topical administration of bromelain and arnica gel combination lead to a significant reduction in periorbital edema and ecchymosis following septorhinoplasty.

\section{INTRODUCTION}

Septorhinoplasty is a commonly performed procedure in the Ear-Nose-Throat (ENT) clinics. In standard septorhinoplasty, osteotomies can cause significant periorbital edema and ecchymosis which result from injury in the vessels passing through the osteotomy areas and broken nasal bones and lead to a significant increase in morbidity. Accordingly, rapid recovery is of prime importance for patients undergoing septorhinoplasty. On the other hand, although edema and ecchymosis can be reduced with careful surgical techniques, they cannot be prevented completely $[1,2]$.

Arnica is a genus of herbaceous plants native to Europe and the mountains of Western North America which has gained increasing popularity in complementary and alternative medicine. Due to its hematopoietic properties, arnica plays a key role in reducing edema and ecchymosis [3,4]. Although its exact mechanism in the reduction of edema and ecchymosis remains unclear, various theories have been proposed. Among these, one theory posits that arnica reduces histamine release via mast cells and another theory proposes that arnica reduces the expression of proinflammatory cytokines as well [3-7]. On the other hand, some of the studies examining the efficacy of arnica have shown its favorable effects on edema, ecchymosis, and pain [8-12].

Bromelain is a mixture of protease enzymes derived from the stems of pineapples which is primarily used for its antiedema, antithrombotic, and fibrinolytic properties [3,13]. Although the exact mechanism of bromelain is not fully elucidated, its main mechanism of action is considered to be through NF-kB inhibition. In invitro studies, bromelain has been shown to reduce prostaglandin E2, thromboxane B2, and interleukin-8. Moreover, bromelain has also been shown to increase blood flow and oxygenation of the injured area [3,1416]. On the other hand, several studies examining the efficacy of bromelain have shown its beneficial effects on edema, ecchymosis, and pain as well [17-20]. 
The present study was designed to investigate the effect of topical bromelain and arnica gel combination on periorbital edema and ecchymosis following septorhinoplasty, which to our knowledge, has never been examined in the literature.

\section{MATERIAL AND METHODS}

Sixty patients who performed open septorhinoplasty (oSRP) with osteotomies were included to the study. Their ages were ranged from 21 to 42 (34 women and 26 men). This study was conducted in accordance with the Declaration of Helsinki and was approved by the local ethics committee. All patients were given about study and written informed consent was obtained from each of them.

Sixty patients were allocated into two groups: in group 1, 30 patients as control and in group 2, 30 patients as study group who were treated with topical bromelain-arnica gel after surgery. Bromelain-arnica gel was applied topically to each patients' ecchymosis and edema around their eyes from postoperative first day to seventh day as three times in a day.

Patients with diabetes mellitus, hypertension, peptic ulcer, psychiatric disorders, known allergy any drug, preoperative use of anticoagulant therapy, before 5 days to the operation, hematologic disorders and fibrinolytic disorders were excluded from the study. We avoided to operate the female patients during or immediately before their menstrual period. In both groups, the patients with complaints of nasal obstruction were diagnosed with nasal septal deviation by means of anterior rhinoscopy and endoscopic nasal examination by the first and second authors.

All the oSRP operations were performed under intubation and general anesthesia. To reduce the introduction of confounding factors, all operations were done by the first and second authors (O Sakallioglu and E Gulmez) using the same technique and equipment. After dorsal hump removal, guided and curved 4-mm lateral osteotomies were used for lateral osteotomies. Lateral osteotomies were made bilaterally without subperiosteal elevation and endonasally by performing a small incision at pyriform apertura just above the level of the anterior end of the inferior turbinate in all patients. Each surgeon operated on an equal number of patients in each group. During the operation, the mean arterial blood pressure was maintained at 70 to $90 \mathrm{~mm} \mathrm{Hg}$ with esmolol infusion. Namely, dorsal hump extraction and medial and lateral osteotomies were done in all patients.

After completing the oSRP operation, antibiotic soaked nonabsorbable packs (Merocel; Medtronic Xomed) were put into the nose bilaterally. The external nasal cast splints were routinely used for all patients. During the first 24 hours postoperatively, patients lied down at 45 degrees head elevated position and ice packs were applied. The nonabsorbable packs of all patients were removed on the second postoperative day. All patients were given the same antibiotics (amoxicilline $1 \mathrm{gr}$ twice in a day for 10 days) and the same analgesics (paracetamol 4 times in a day dor 10 days).

Scoring of eyelid edema and periorbital ecchymosis were evaluated on the first, third and seventh postoperative days using scale of 0 to 4 used by observers, Kara and Gokalan (Figures 1,2) [1].

The IBM SPSS Statistics 21 was used for all statistical analysis. One-way analysis of variance (ANOVA) or Kruskal-Wallis ANOVA was used to compare variables between the groups. $\mathrm{P}$ values $<0.05$ was considered as statistically significant.

\section{RESULTS}

A total of 60 patients who performed oSRP with osteotomies between age of 21 and 42 years (34 women and 26 men, mean age $\pm \mathrm{SD}, 29 \pm 9$ years) were included to the study. Of them 30 patients were as control (ages 21-39 years, 12 men, 18 women, mean age \pm SD, $28 \pm 7$ years) and 30 patients were as study group (ages 21-42 years, 14 men, 16 women, mean age $\pm \mathrm{SD}, 27 \pm 8$ years). No statistically significant difference was observed among the groups in terms of age and sex.

We observed that the administration of topical bromelain-arnica gel after surgery was effective clinically and statistically in decreasing the score of both edema and ecchymosis in oSRP with ostetomies. In group 2 
patients, periorbital edema and ecchymosis scores were significantly lower compared to control group (p $<$ 0.05). Graphics of postoperative edema and ecchymosis scores were showed as Figures 3-6. No complication associated with topical bromelain-arnica gel use or oSRP surgical procedure was observed.

\section{DISCUSSION}

Septorhinoplasty is an effective cosmetic surgery widely applied and accepted around the world. In this procedure, complications involving skin and soft tissues may occur due to the force applied to reshape the nose and these complications significantly affect patient satisfaction [21-23]. Edema and ecchymosis can be distressing for patients in the early postoperative period. Of note, edema in the first postoperative 24 hours may affect visual acuity and ecchymosis may lead to disruption of patients' social activities due to increased pigmentation [24]. Although numerous techniques have been developed to reduce edema and ecchymosis since years, post-rhinoplasty care remains controversial [25,26]. As rhinoplasty remains a demanding and popular operation, it is important to ensure that clinicians follow best practices to reduce morbidity $[26,27]$. To the best of our knowledge, this is the first study in the literature to investigate the effect of topically usage of bromelain and arnica gel combination on periorbital edema and ecchymosis following septorhinoplasty.

A previous study evaluated the effect of arnica and bromelain combination on ecchymosis after blepharoplasty. A total of 130 patients received the tablet forms of arnica and bromelain for a total of two weeks, one week before surgery and another week after surgery, while the control group received no treatment. The authors concluded that no significant difference was found between the two groups with regard to ecchymosis [28]. But, in this study, we applied bromelain-arnica gel combination topically to the patients' ecchymosis and edema around their eyes, and we also observed that topical application of bromelain-arnica gel combination was effective to significantly decrease patients' both ecchymosis and edema.

Another study evaluated the effect of topical application of arnica and mucopolysaccharide polysulphate in open rhinoplasty on periorbital edema and ecchymosis and divided the patients into three groups: group I received postoperative arnica cream treatment, group II received postoperative mucopolysaccharide polysulphate cream treatment, and Group III (control group) included patients who received no postoperative treatment. The authors found a significant difference between groups I and II and the control group with regard to periorbital edema and ecchymosis, while there was no significant difference between groups I and II. The authors proposed that a rapid regression of edema and ecchymosis could be achieved by local treatments of arnica and mucopolysaccharide polysulphate cream [29].

Sakallioglu et al. examined the effect of tranexamic acid and methylprednisolone on periorbital edema and ecchymosis in patients that underwent open septorhinoplasty. The authors divided patients into three groups: group I (control group) received no postoperative treatment, group II received oral tranexamic acid, and group III received intravenous methylprednisolone therapy. Groups II and III had significantly lower periorbital edema and ecchymosis scores compared to the control group, while no significant difference was found between groups II and III [30]. A prospective, randomized triple-blinded study examined the effect of dexamethasone and tranexamic acid on post-rhinoplasty periorbital edema and ecchymosis and divided the patients into four groups: group D received dexamethasone, group $\mathrm{T}$ received tranexamic acid, group DT received dexamethasone and tranexamic acid, and group P (control group) received no medication. All the drugs were administered intravenously. The results indicated that the periorbital edema and ecchymosis scores were significantly lower in groups D, T, and DT, compared to the control group, whereas no significant difference was found among groups D, T, and DT [31].

Totonchi et al. investigated the effect of steroids and arnica following rhinoplasty and divided the patients into three groups: group P received steroids, group A received arnica, and group C (control group) received no medication. The results demonstrated that both steroids and arnica could be effective in reducing edema during the early postoperative period [32]. Literature indicates that preoperative steroid administration could be a preventive measure to reduce edema and ecchymosis in rhinoplasty $[1,33,34]$. A previous meta-analysis reported that perioperative administration of repeated doses of steroids was more effective in reducing periorbital edema and ecchymosis than single-dose steroid administration [35]. Combined use of lidocaine 
and adrenaline reduces intraoperative bleeding and postoperative pain in patients undergoing rhinoplasty while it may not lead to reduction in postoperative edema and ecchymosis [36].

In a prospective randomized controlled double-blinded study, Chaiet et al. evaluated the efficacy of perioperative use of Arnica montana on post-rhinoplasty ecchymosis and found that Arnica montana led to a significant reduction in ecchymosis compared to the control group [37]. Kara et al. found that the subperiosteal tunnel created before lateral osteotomy led to a significant increase in periorbital ecchymosis and also increased subconjunctival ecchymosis though insignificantly. Based on these findings, the authors recommended that the creation of a subperiosteal tunnel before lateral osteotomy should be avoided [38]. Another study by Sakallioglu et al. compared the effect of open and closed septorhinoplasty procedures on periorbital edema and ecchymosis and found no significant difference between the two techniques [39]. Kelles et al. investigated the efficacy of local heparinoids in the reduction of periorbital edema and ecchymosis and found that local administration of heparinoids following rhinoplasty had no significant effect on the prevention of periorbital edema and ecchymosis [40]. A recent systematic review indicated that favorable outcomes were obtained in terms of edema, ecchymosis, and pain control in surgical operations using arnica and bromelain, including not only rhinoplasty but also orthopedic surgeries. Based on these findings, the authors suggested that arnica and bromelain could be used not only in rhinoplasty but also in surgical operations that are suitable in terms of edema, ecchymosis, and pain control [41].

Septorhinoplasty is highly popular and the number of patients undergoing this procedure is growing worldwide. But, periorbital edema and ecchymosis following septorhinoplasty can cause to significant increase in morbidity and a significant decrease in patient satisfaction. Although, there are numerous studies investigating the reduction of periorbital edema and ecchymosis, and post-rhinoplasty care remains controversial. In this study, we investigated the efficacy of topical administration of bromelain and arnica gel combination in the reduction of periorbital edema and ecchymosis following septorhinoplasty, and we compared the results with those of control group in a randomized fashion. In conclusion, this study indicated that topical administration of bromelain and arnica gel combination lead to a significant reduction in periorbital edema and ecchymosis following septorhinoplasty.

Conflict of interest: There is no conflict of interest for any authors.

Financial disclosure: There is no financial assistance

\section{REFERENCES}

1. Kara CO, Gökalan I. Effects of single-dose steroid usage on edema, ecchymosis, and intraoperative bleeding in rhinoplasty. Plastic and reconstructive surgery. 1999;104(7):2213-8.

2. Gersema L, Baker K. Use of corticosteroids in oral surgery. Journal of oral and maxillofacial surgery. 1992;50(3):270-7.

3. Ho D, Jagdeo J, Waldorf HA. Is there a role for arnica and bromelain in prevention of post-procedure ecchymosis or edema? A systematic review of the literature. Dermatologic surgery. 2016;42(4):445-63.

4. Kouzi SA, Nuzum DS. Arnica for bruising and swelling. American Journal of Health-System Pharmacy. 2007;64(23):2434-43.

5. Lyss G, Schmidt TJ, Merfort I, Pahl HL. Helenalin, an anti-inflammatory sesquiterpene lactone from Arnica, selectively inhibits transcription factor NF-xB. Biological chemistry. 1997;378(9):951-62.

6. Bedi MK, Shenefelt PD. Herbal therapy in dermatology. Archives of dermatology. 2002;138(2):232-42.

7. Verma N, Tripathi SK, Sahu D, Das HR, Das RH. Evaluation of inhibitory activities of plant extracts on production of LPS-stimulated pro-inflammatory mediators in J774 murine macrophages. Molecular and cellular biochemistry. 2010;336(1-2):127-35.

8. Kotlus BS, Heringer DM, Dryden RM. Evaluation of homeopathic Arnica montana for ecchymosis after 
upper blepharoplasty: a placebo-controlled, randomized, double-blind study. Ophthalmic Plastic \& Reconstructive Surgery. 2010;26(6):395-7.

9. Robertson A, Suryanarayanan R, Banerjee A. Homeopathic Arnica montana for post-tonsillectomy analgesia: a randomised placebo control trial. Homeopathy. 2007;96(1):17-21.

10. Jeffrey S, Belcher H. Use of Arnica to relieve pain after carpal-tunnel release surgery. Alternative Therapies in Health and Medicine. 2002;8(2):66.

11. Kang JY, Tran KD, Seiff SR, Mack WP, Lee WW. Assessing the effectiveness of Arnica montana and Rhododendron tomentosum (Ledum palustre) in the reduction of ecchymosis and edema after oculofacial surgery: preliminary results. Ophthalmic Plastic \& Reconstructive Surgery. 2017;33(1):47-52.

12. Hart O, Mullee MA, Lewith G, Miller J. Double-blind, placebo-controlled, randomized clinical trial of homoeopathic arnica C30 for pain and infection after total abdominal hysterectomy. Journal of the Royal Society of Medicine. 1997;90(2):73-8.

13. Reider N, Komericki P, Hausen B, Fritsch P, Aberer W. The seamy side of natural medicines: contact sensitization to arnica (Arnica montana L.) and marigold (Calendula officinalis L.). Contact Dermatitis. 2001;45(5):269-72.

14. Maurer H. Bromelain: biochemistry, pharmacology and medical use. Cellular and Molecular Life Sciences CMLS. 2001;58(9):1234-45.

15. Bhui K, Prasad S, George J, Shukla Y. Bromelain inhibits COX-2 expression by blocking the activation of MAPK regulated NF-kappa B against skin tumor-initiation triggering mitochondrial death pathway. Cancer letters. 2009;282(2):167-76.

16. Wu S-Y, Hu W, Zhang B, Liu S, Wang J-M, Wang A-M. Bromelain ameliorates the wound microenvironment and improves the healing of firearm wounds. Journal of Surgical Research. 2012;176(2):503-9.

17. Isola G, Matarese M, Ramaglia L, Iorio-Siciliano V, Cordasco G, Matarese G. Efficacy of a drug composed of herbal extracts on postoperative discomfort after surgical removal of impacted mandibular third molar: A randomized, triple-blind, controlled clinical trial. Clinical oral investigations. 2019;23(5):2443-53.

18. Ghensi P, Cucchi A, Creminelli L, Tomasi C, Zavan B, Maiorana C. Effect of oral administration of bromelain on postoperative discomfort after third molar surgery. Journal of Craniofacial Surgery. 2017;28(2):e191e7.

19. Singh T, More V, Fatima U, Karpe T, Aleem MA, Prameela J. Effect of proteolytic enzyme bromelain on pain and swelling after removal of third molars. Journal of International Society of Preventive \& Community Dentistry. 2016;6(Suppl 3):S197.

20. Bormann KH, Weber K, Kloppenburg H, Koch A, Meiser P, Gellrich NC. Perioperative Bromelain Therapy after Wisdom Teeth Extraction-A Randomized, Placebo-Controlled, Double-Blinded, Three-Armed, Cross-Over Dose-Finding Study. Phytotherapy Research. 2016;30(12):2012-9.

21. Coroneos CJ, Voineskos SH, Cook DJ, Farrokhyar F, Thoma A. Perioperative corticosteroids reduce short-term edema and ecchymosis in rhinoplasty: a meta-analysis. Aesthetic surgery journal. 2016;36(2):13646.

22. Koc S, Gürbüzler L, Yaman H, Eyibilen A, Süren M, Kaya Z, et al. The effectiveness of steroids for edema, ecchymosis, and intraoperative bleeding in rhinoplasty. American Journal of Rhinology \& Allergy. 2011;25(2):e95-e8.

23. Saedi B, Sadeghi M, Fekri K. Comparison of the effect of corticosteroid therapy and decongestant on reducing rhinoplasty edema. American journal of rhinology \& allergy. 2011;25(4):e141-e4. 
24. Taskin U, Yigit O, Bilici S, Kuvat SV, Sisman AS, Celebi S. Efficacy of the combination of intraoperative cold saline-soaked gauze compression and corticosteroids on rhinoplasty morbidity. Otolaryngology-Head and Neck Surgery. 2011;144(5):698-702.

25. Ong AA, Farhood Z, Kyle AR, Patel KG. Interventions to decrease postoperative edema and ecchymosis after rhinoplasty: a systematic review of the literature. Plastic and Reconstructive Surgery. 2016;137(5):144862.

26. Kelley BP, Koshy J, Hatef D, Hollier Jr LH, Stal S. Packing and postoperative rhinoplasty management: a survey report. Aesthetic surgery journal. 2011;31(2):184-9.

27. Lee HS, Yoon HY, Kim IH, Hwang SH. The effectiveness of postoperative intervention in patients after rhinoplasty: a meta-analysis. European archives of oto-rhino-laryngology. 2017;274(7):2685-94.

28. Seamont D, Vrcek I, Nakra T, Mancini R. Arnica and Bromelain for Blepharoplasty-Associated Ecchymosis. The American Journal of Cosmetic Surgery. 2018;35(3):130-4.

29. Simsek G, Sari E, Kilic R, Bayar Muluk N. Topical application of arnica and mucopolysaccharide polysulfate attenuates periorbital edema and ecchymosis in open rhinoplasty: a randomized controlled clinical study. Plastic and Reconstructive Surgery. 2016;137(3):530e-5e.

30. Sakallioglu Ö, Polat C, Soylu E, Düzer S, Orhan I, Akyigit A. The efficacy of tranexamic acid and corticosteroid on edema and ecchymosis in septorhinoplasty. Annals of plastic surgery. 2015;74(4):392-6.

31. Mehdizadeh M, Ghassemi A, Khakzad M, Mir M, Nekoohesh L, Moghadamnia A, et al. Comparison of the effect of dexamethasone and tranexamic acid, separately or in combination on post-rhinoplasty edema and ecchymosis. Aesthetic Plastic Surgery. 2018;42(1):246-52.

32. Totonchi A, Guyuron B. A randomized, controlled comparison between arnica and steroids in the management of postrhinoplasty ecchymosis and edema. Plastic and reconstructive surgery. 2007;120(1):271-4.

33. Gurlek A, Fariz A, Aydogan H, Ersoz-Ozturk A, Eren AT. Effects of different corticosteroids on edema and ecchymosis in open rhinoplasty. Aesthetic plastic surgery. 2006;30(2):150-4.

34. Kargi E, Hosnuter M, Babucçu O, Altunkaya H, Altinyazar C. Effect of steroids on edema, ecchymosis, and intraoperative bleeding in rhinoplasty. Annals of plastic surgery. 2003;51(6):570-4.

35. Hwang SH, Lee JH, Kim BG, Kim SW, Kang JM. The efficacy of steroids for edema and ecchymosis after Rhinoplasty: A meta-analysis. The Laryngoscope. 2015;125(1):92-8.

36. Gun R, Yorgancılar E, Yıldırım M, Bakır S, Topcu I, Akkus Z. Effects of lidocaine and adrenaline combination on postoperative edema and ecchymosis in rhinoplasty. International journal of oral and maxillofacial surgery. 2011;40(7):722-9.

37. Chaiet SR, Marcus BC. Perioperative Arnica montana for reduction of ecchymosis in rhinoplasty surgery. Annals of Plastic Surgery. 2016;76(5):477-82.

38. Kara CO, Kara InG, Topuz B. Does creating a subperiosteal tunnel influence the periorbital edema and ecchymosis in rhinoplasty? Journal of oral and maxillofacial surgery. 2005;63(8):1088-90.

39. Sakallioglu Ö, Cingi C, Polat C, Soylu E, Akyigit A, Soken H. Open versus closed septorhinoplasty approaches for postoperative edema and ecchymosis. Journal of Craniofacial Surgery. 2015;26(4):1334-7.

40. Kelles M, Erdem T, Firat Y, Kalcioglu MT, Akarcay M, Selimoglu E, et al. Efficacy of local heparinoids on preventing edema and ecchymosis after rhinoplasty. Kulak burun bogaz ihtisas dergisi: KBB = Journal of ear, nose, and throat. 2010;20(4):191.

41. Knackstedt R, Gatherwright J. Perioperative Homeopathic Arnica and Bromelain: Current Results and Future Directions. Annals of Plastic Surgery. 2020;84(3):e10-e5. 
Figure 1. Grading scale for periorbital edema. 0, none. $(+)$ 1, minimal. $(+)$ 2, extending onto the iris. $(+)$ 3 , covering the iris. $(+) 4$, massive edema.

Figure 2. Grading scale for periorbital ecchymosis. $(+) 1$, extending to the medial canthus. $(+) 2$, extending to the pupil. $(+) 3$, past the pupil. $(+) 4$, extending onto the lateral canthus.

Figure 3. Mean ecchymosis scores of upper eyelids. POD, indicates postoperative day.

Figure 4. Mean ecchymosis scores of lower eyelids.

Figure 5. Mean edema scores of upper eyelids.

Figure 6. Mean edema scores of lower eyelids.
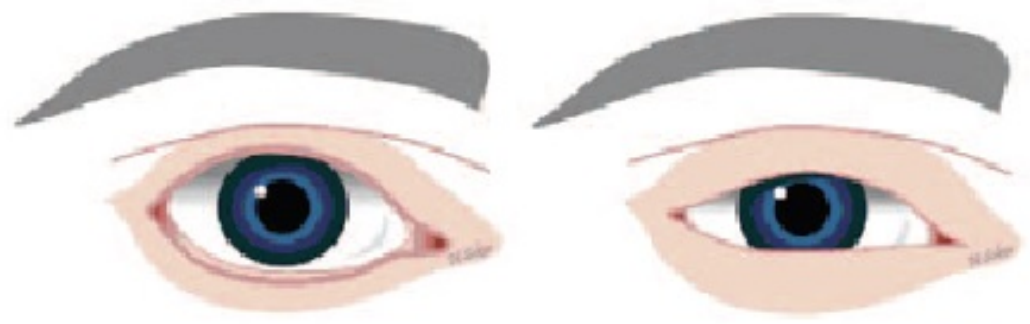

$(+) 1$

$(+) 2$
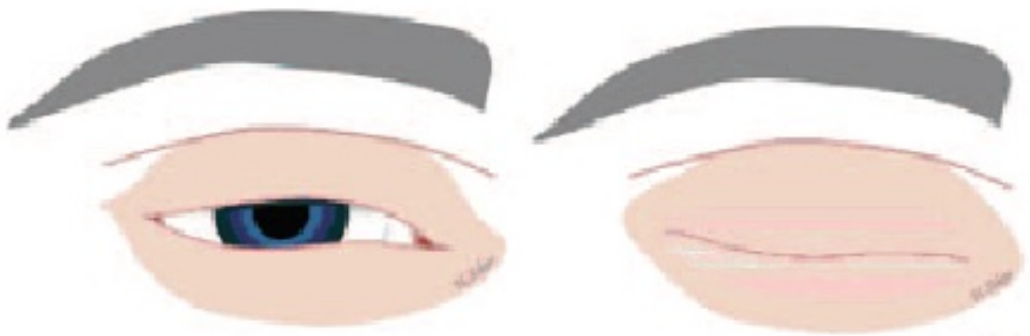

$(+) 3$

$(+) 4$ 

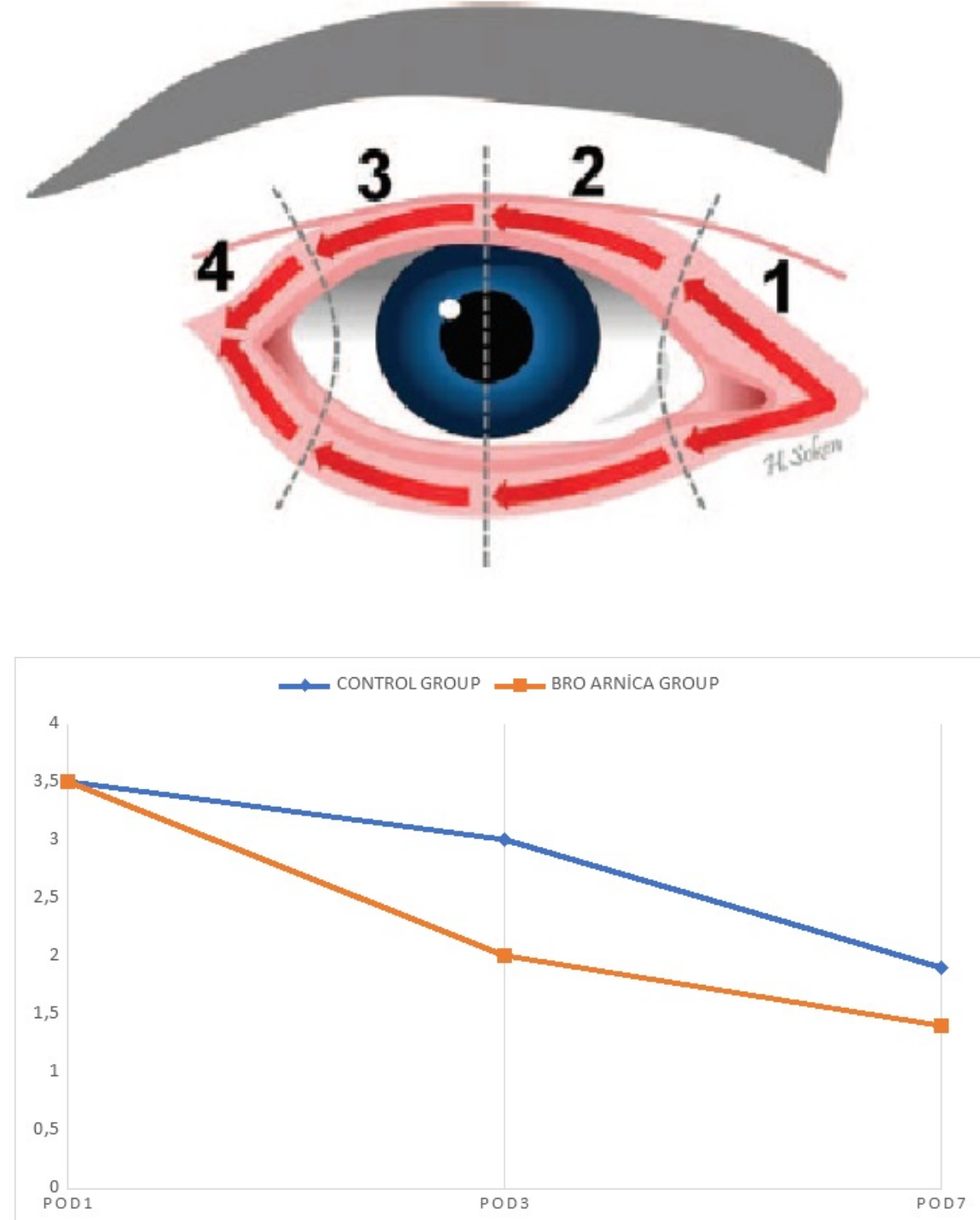

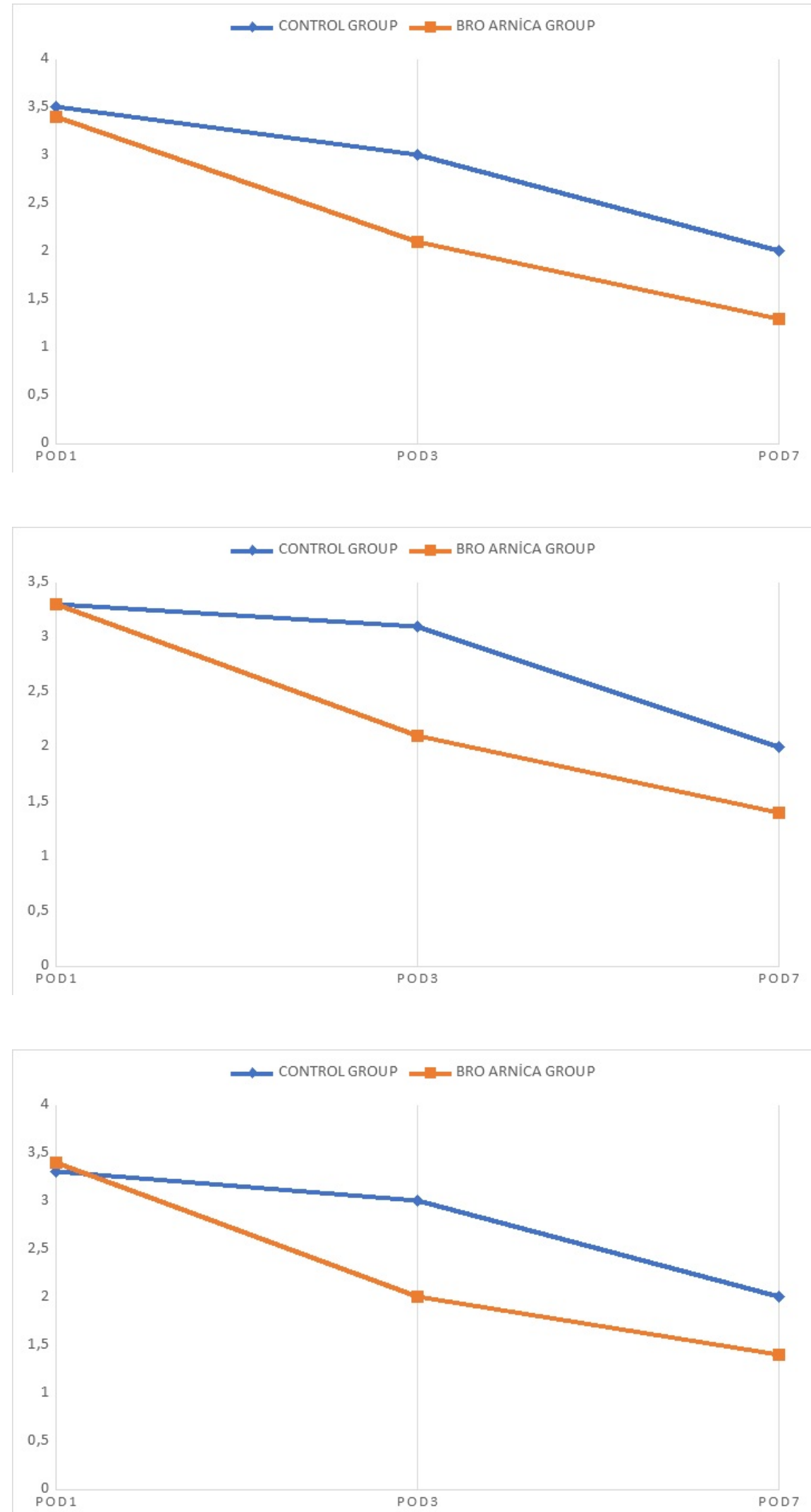